\title{
Midlife cardiovascular fitness and dementia
}

\section{A 44-year longitudinal population study in women}

Helena Hörder, PhD, Lena Johansson, PhD, XinXin Guo, MD, PhD, Gunnar Grimby, MD, Silke Kern, MD, PhD, Svante Östling, MD, and Ingmar Skoog, MD

Neurology ${ }^{\circledR}$ 2018;90:e1298-e1305. doi:10.1212/WNL.0000000000005290

\section{Abstract}

\section{Objective}

To investigate whether greater cardiovascular fitness in midlife is associated with decreased dementia risk in women followed up for 44 years.

\section{Methods}

A population-based sample of 1,462 women 38 to 60 years of age was examined in 1968. Of these, a systematic subsample comprising 191 women completed a stepwise-increased maximal ergometer cycling test to evaluate cardiovascular fitness. Subsequent examinations of dementia incidence were done in 1974, 1980, 1992, 2000, 2005, and 2009. Dementia was diagnosed according to DSM-III-R criteria on the basis of information from neuropsychiatric examinations, informant interviews, hospital records, and registry data up to 2012. Cox regressions were performed with adjustment for socioeconomic, lifestyle, and medical confounders.

\section{Results}

Compared with medium fitness, the adjusted hazard ratio for all-cause dementia during the 44-year follow-up was 0.12 (95\% confidence interval [CI] 0.03-0.54) among those with high fitness and 1.41 (95\% CI 0.72-2.79) among those with low fitness. High fitness delayed age at dementia onset by 9.5 years and time to dementia onset by 5 years compared to medium fitness.

\section{Conclusions}

Among Swedish women, a high cardiovascular fitness in midlife was associated with a decreased risk of subsequent dementia. Promotion of a high cardiovascular fitness may be included in strategies to mitigate or prevent dementia. Findings are not causal, and future research needs to focus on whether improved fitness could have positive effects on dementia risk and when during the life course a high cardiovascular fitness is most important.

\author{
Correspondence \\ Dr. Hörder \\ Helena.Horder@neuro.gu. \\ se
}

\section{RELATED ARTICLE}

\section{Editorial}

Fitness and dementia risk: Further evidence of the heart-brain connection

Page 675

From the Neuropsychiatric Epidemiology Unit (H.H., L.J., X.G., S.K., S.Ö., I.S.), Institute of Neuroscience and Physiology, Sahlgrenska Academy, Centre for Ageing and Health-AGECAP, and Department of Clinical Neuroscience (G.G.), Institute of Neuroscience and Physiology, Sahlgrenska Academy, University of Gothenburg, Sweden.

Go to Neurology.org/N for full disclosures. Funding information and disclosures deemed relevant by the authors, if any, are provided at the end of the article. 


\section{Glossary}

CI = confidence interval; FINGER = Finnish Geriatric Intervention Study to Prevent Cognitive Impairment and Disability; PPSW $=$ Prospective Population Study of Women; RCT $=$ randomized controlled trial.

Systematic reviews and meta-analyses of observational studies constantly link physical activity to preserved cognitive functioning and decreased risk for dementia. ${ }^{1-3}$ These studies are limited by reliance on self-reported physical activity and not objectively assessed fitness. Thus, it remains unclear whether the association between physical activity and dementia is mediated by social and cognitive stimulation rather than by level of physical fitness. Furthermore, most studies are conducted in people $>60$ years of age at baseline, and few have a follow-up of $>20$ years (mean follow-up 3-7 years), making causal inferences difficult. ${ }^{4-6}$

Aerobic exercise programs aiming at improving cardiovascular fitness seem to have moderate effects on cognitive function among healthy older person. ${ }^{5,7}$ However, current data from randomized controlled trials (RCTs) are insufficient to show that these improvements are due to improved cardiovascular fitness. $^{5}$

Presently, no RCTs and very few long-term prospective studies have been able to relate fitness to dementia incidence. The US Cooper Center Longitudinal Study recently reported that a high midlife fitness, assessed by a maximal treadmill test, was associated with lower risk of developing dementia over a mean follow-up period of 24 years. $^{8}$ Furthermore, 1 large register study among men in Sweden reported that low cardiovascular fitness, assessed with a bicycle ergometer test at 18 years of age, was associated with an increased risk of earlyonset ( $<60$ years) dementia. ${ }^{9}$ This is interesting because the etiology of early-onset dementia is supposed to have strong genetic components. Finally, 1 population study from Finland found that poor self-rated fitness in mid to late life was associated with increased dementia risk over 25 years of followup. ${ }^{10}$ Thus, there is a need for studies that examine objective fitness before old age with follow-up of dementia until very old age.

Midlife has been suggested as a "sensitive period" for the effect of cardiovascular risk factors on dementia. ${ }^{11,12}$ We therefore tracked dementia incidence for a period of 44 years among women enrolled in the Prospective Population Study of Women (PPSW) who performed a test of maximal cardiovascular fitness in midlife.

\section{Methods}

The study is part of the PPSW, which was initiated in $1968 .{ }^{13}$ Women born in 1908, 1914, 1918, 1922, and 1930 were systematically sampled from the Swedish Population Register on the basis of specific birth dates. Among those sampled,
1,462 women were examined (participation rate 90\%). The details and procedures for the examination of the original sample have been described elsewhere. ${ }^{13}$ A systematic subsample (born on the sixth day of uneven months, e.g., January, March, etc) were admitted to an exercise test, and 191 took part (response rate $81 \%$ ): 29 who were 38 years, 41 who were 46 years, 37 who were 50 years, 47 who were 54 years, and 37 who were 60 years of age. ${ }^{14}$ Follow-ups for dementia diagnoses were performed in 1974 to 1975 ( $\mathrm{n}=174,8$ had died, 9 refused), 1980 to 1981 ( $\mathrm{n}=147,20$ had died, 24 refused), 1992 to 1993 ( $\mathrm{n}=99,57$ had died, 35 refused), 2000 to 2001 ( $\mathrm{n}=68,92$ had died, 31 refused), 2005 to $2006(\mathrm{n}=46,118$ had died, 27 refused), and 2009 to 2010 ( $n=13,151$ had died, 27 refused). Cases of dementia were also identified via the Swedish Hospital Discharge Register until December 2012.

Participants in the exercise test did not differ from the total sample in age or in cumulative dementia incidence $(23.0 \%$ vs $22.1 \%, p=0.780)$.

\section{Standard protocol approvals, registrations, and patient consents}

The Ethics Committee of the University of Gothenburg approved the study. All women gave informed consent to participate in accordance with the provisions of the Declaration of Helsinki.

\section{Work capacity}

Cardiovascular fitness was tested at baseline in 1968 by a stepwise-increased ergometer cycling test until exhaustion that was supervised by a physician. Details on the full procedure and exclusion criteria have been described previously. ${ }^{14}$ Briefly, after initial submaximal tests of 6 minutes on 200 kilopond $\mathrm{m} / \mathrm{min}(32 \mathrm{~W})$ and 400 kilopond $\mathrm{m} / \mathrm{min}$ (64 $\mathrm{W})$, the test was interrupted for 5 minutes before the women were brought to maximal workload. The level of maximal workload was chosen on basis of the results from the preceding submaximal test with the aim of achieving an approximate working time of 6 minutes before voluntary fatigue. If the person had not reached her limit of exhaustion, the workload was increased by an additional 50 to 100 kilopond $\mathrm{m} / \mathrm{min}$ toward the end of the test. During the period of maximal work, heart rate and ECG were registered every minute, blood pressure was registered after 1 and 2 minutes, and respiratory frequency and perceived exertion according to the Borg-scale ${ }^{15}$ were noted after 3 minutes and then every minute. The maximal exercise test aimed at arriving at maximal subjective exhaustion as indicated by the Borg scale ${ }^{15}$; altogether, 93\% perceived their maximal load as strenuous (scale point $\geq 15$ ) and half of the participants as very, very strenuous (scale point 19-20). ${ }^{14}$ The term peak workload is 
used here because no objective criteria were used for reaching the maximal workload, corresponding to maximal oxygen uptake.

Among 20 women, the test was interrupted during the submaximal test because of changes in ECG $(n=6)$, too high blood pressure $(n=3)$, claudication $(n=2)$, chest pain $(n=$ $1)$, insufficient cooperation $(n=2)$, or other reasons $(n=$ 6). ${ }^{14}$ For analytic purposes, these women were categorized as having low fitness. The main results did not change when these persons were excluded.

\section{Neuropsychiatric examinations and dementia diagnosis}

The neuropsychiatric examinations were performed by psychiatrists in 1968 to 1969,1974 to 1975,1980 to 1981 , and 1992 to 1993 and by experienced psychiatric research nurses in 2000 to 2003, 2005 to 2006, and 2009 to 2010. The examinations were semistructured and included psychiatric interviews, observations of mental symptoms, neuropsychiatric tests, and close informant interviews. ${ }^{16}$

The diagnosis of dementia was based on information from psychiatric examinations, close informant interviews, medical records, and the Swedish Hospital Discharge Registry, as described in detail previously. ${ }^{16}$ For participants in the neuropsychiatric examinations, dementia diagnoses were made by geriatric psychiatrists after reviewing information from both neuropsychiatric examinations and the close informant interview. The diagnosis was made if the participant had dementia according to both sources of information or if there was clear evidence of dementia from 1 source and subthreshold symptoms in the other.

For individuals lost to follow-up, dementia diagnoses were based on information from medical records evaluated by geriatric psychiatrists in consensus conferences and from the Swedish Hospital Discharge Register. The latter provided diagnostic information until December 2012 for all individuals discharged from hospitals on a nationwide basis since 1978. ${ }^{17}$ We have previously reported that the Hospital Discharge Register detects $44 \%$ of persons diagnosed at the examinations. $^{18}$

See supplemental data on dementia diagnosis in appendix e-1 (links.lww.com/WNL/A330).

\section{Confounders}

Potential covariates were chosen on the basis of previous research ${ }^{4}$ and biologically relevant variables at the baseline examination in 1968. Education was dichotomized as compulsory (6 years for those born in 1908-1922, 7 years for those born in 1930) or more than compulsory. Smoking was classified as current/ex-smoker vs never smoker. Physical activity during leisure and occupation was assessed according to a slightly modified version of the 4-level SaltinGrimby scale. ${ }^{19,20}$ Level 1 (almost completely inactive) was classified as physical inactivity. Wine consumption was dichotomized as never drinker or drinker. Hypertension was defined as systolic blood pressure $\geq 140 \mathrm{~mm} \mathrm{Hg}$, diastolic blood pressure $\geq 90 \mathrm{~mm} \mathrm{Hg}$, and/or taking antihypertensive medication. Body height was measured to the nearest centimeter and weight to the nearest $0.1 \mathrm{~kg}$. Body mass index was calculated as kilograms per meter squared. Serum cholesterol and triglyceride levels were assessed after an overnight fast. Diabetes mellitus was self-reported and defined as diagnosis told by a physician or being on antidiabetic therapy (insulin and/or tablets). History of myocardial infarction and angina pectoris was self-reported and defined as a diagnosis told by a physician. The diagnosis of stroke was based on information from participants and key informants, the Swedish Hospital Discharge Registry, and hospital medical records.

\section{Statistics}

Incidence proportions of dementia are presented as cumulative incidence. Differences between fitness groups were analyzed with the $\chi^{2}$ test for dichotomous variables and 1-way analysis of variance for continuous variables. We calculated Cox proportional hazards models with all-cause dementia as the outcome and fitness as the predictor. Person-years were calculated from date of baseline examination to (1) time of dementia onset, (2) date of death according to the Swedish Population Register, or (3) December 31, 2012, for all other participants.

For analytic purposes, fitness was described as follows: the crude peak workload categorized into quintiles, but because the 3 middle groups had very similar incidence of dementia, analyses were performed with peak workload categorized into low ( $\leq 80 \mathrm{~W}$ or interrupted at submaximal workload), medium (88-112 W), and high ( $\geq 120 \mathrm{~W})$ fitness; and peak workload/ body weight transformed into stanine scores and categorized as low (stanine score 1-3 or interrupted at submaximal workload), medium (stanine score 4-6), and high (stanine score 7-9) fitness.

In model 1 , we included age and body height as confounders. In model 2, further confounders were included if bivariate associations in logistic regressions had values of $p<0.20$ with all-cause dementia (i.e., serum triglycerides $p<0.001$, smoker $p=0.18$ ) or with fitness (i.e., hypertension $p<0.001$, wine consumption $p=0.008$, physical inactivity $p=0.161$, income $p=0.010)$.

All analyses were done with IBM SPSS Statistics 22 (IBM, Armonk, NY). Tests were 2 sided, and the level of significance was set to $p<0.05$.

\section{Results}

The mean peak workload at the ergometer cycling test in 1968 was 103 (SD 21) W. The midlife characteristics of the study 
Table 1 Characteristics of women at baseline examination in midlife (year 1968) stratified by cardiovascular fitness from the crude peak workload $(n=191)$

\begin{tabular}{|c|c|c|c|c|c|}
\hline & $\begin{array}{l}\text { All } \\
(n=191)\end{array}$ & $\begin{array}{l}\text { Low fitness } \\
(n=59)\end{array}$ & $\begin{array}{l}\text { Medium fitness } \\
(\mathrm{n}=92)\end{array}$ & $\begin{array}{l}\text { High fitness } \\
(n=40)\end{array}$ & $\begin{array}{l}p \text { Value for } \\
\text { trend }\end{array}$ \\
\hline Age, mean (SD), y & $50.2(7.0)$ & $52.3(6.7)$ & $49.6(6.9)$ & $48.6(7.0)$ & 0.225 \\
\hline Compulsory education only, n (\%) & $132(69)$ & $44(75)$ & $60(65)$ & $28(70)$ & 0.530 \\
\hline No own income, $\mathrm{n}(\%)$ & $55(29)$ & $22(37)$ & $28(30)$ & $5(13)$ & 0.010 \\
\hline Never smoker, n (\%) & $110(58)$ & $38(64)$ & $49(53)$ & $23(58)$ & 0.609 \\
\hline Married, n (\%) & $147(77)$ & $48(81)$ & $70(76)$ & $29(72)$ & 0.375 \\
\hline Wine consumption: never drinker, n (\%) & $106(56)$ & $40(68)$ & $50(54)$ & $16(40)$ & 0.008 \\
\hline Physically inactive at leisure, $n$ (\%) & $29(15)$ & $10(17)$ & $16(17)$ & $3(7)$ & 0.161 \\
\hline Physically inactive occupation, n (\%) & $10(5)$ & $5(8)$ & $5(5)$ & $0(0)$ & 0.214 \\
\hline Hypertension (>140/90 mm Hg) or treatment, $n(\%)$ & $93(49)$ & $40(68)$ & $41(45)$ & $12(30)$ & $<0.001$ \\
\hline Systolic blood pressure, mean (SD), mm Hg & $138.5(24.2)$ & $148.6(24.8)$ & $137.1(24.3)$ & $126.8(16.4)$ & $<0.001$ \\
\hline Diastolic blood pressure, mean (SD), mm Hg & $84.6(11.4)$ & $87.2(12.9)$ & $84.6(11.1)$ & $80.6(8.4)$ & 0.028 \\
\hline Body mass index, mean (SD), kg/m² & $24.6(4.0)$ & $24.7(4.8)$ & $24.3(3.4)$ & $24.5(4.4)$ & 0.902 \\
\hline Weight, mean (SD), kg & $65.4(11.4)$ & $64.9(11.7)$ & $65.0(8.5)$ & $67.0(16.0)$ & 0.590 \\
\hline Height, mean (SD), cm & $163.5(5.6)$ & $162.1(4.9)$ & $163.8(5.6)$ & $164.9(6.4)$ & 0.163 \\
\hline Cholesterol, mean (SD), mmol/L & $7.1(1.8)$ & $7.1(1.2)$ & $7.2(2.3)$ & $6.8(1.0)$ & 0.303 \\
\hline Triglycerides, mean (SD), mmol/L & $1.2(0.8)$ & $1.2(0.4)$ & $1.3(1.1)$ & $1.2(0.6)$ & 0.558 \\
\hline Stroke until 2001, n (\%) & $29(15)$ & $11(19)$ & $14(15)$ & $4(10)$ & 0.246 \\
\hline Diabetes mellitus until 2001, n (\%) & $15(8)$ & $4(7)$ & $8(9)$ & $3(8)$ & 0.853 \\
\hline Myocardial infarction until 2001, n (\%) & $25(13)$ & $9(15)$ & $8(9)$ & $8(20)$ & 0.655 \\
\hline Persons still alive in 2012, n (\%) & $28(14.7)$ & $6(10.1)$ & $15(16.3)$ & $7(17.5)$ & 0.279 \\
\hline Age at death, mean (SD), y & $80.4(11.2)$ & $80.1(10.6)$ & $80.3(11.0)$ & $81.3(12.8)$ & 0.882 \\
\hline
\end{tabular}

Fitness is assessed by a stepwise-increased ergometer cycling test until exhaustion. Low fitness = crude peak workload $<72 \mathrm{~W}$ or test interrupted at $<64 \mathrm{~W}$; medium fitness = crude peak workload 80 to $112 \mathrm{~W}$; and high fitness = crude peak workload $\geq 122 \mathrm{~W}$. The $p$ value for trend is by $\chi^{2}$ test for dichotomous data and analysis of variance for continuous data.

population are presented in table 1 . Women with high fitness more often had their own income and higher wine consumption and less often had hypertension compared to those with medium or low fitness. Mean age at death was 80.4 years, and $15 \%$ were still alive at the end of the study. We found no statistical difference between the groups in age at death or survival.

In total, 44 women (23.0\%) developed dementia during 5,544 person-years of follow-up from 1968 to 2012. The mean follow-up period was 29 years. Diagnoses included 20 cases of pure Alzheimer dementia, 8 of vascular dementia, 12 of mixed dementia, and 4 of other dementias. Altogether, 28 cases of dementia were diagnosed on the basis of information from the examinations, and another 16 (36\%) were diagnosed from registers and case records. The mean time to dementia onset from midlife examination was 29.0 years, and the mean age at dementia onset was 80.5 years.
Table 2 shows the relation between peak workload and $\mathrm{cu}-$ mulative dementia incidence. It is noteworthy that the dementia incidence among those who interrupted the test at submaximal workload was $45 \%$.

When categorized into 3 fitness groups based on the peak workload, the cumulative incidence of all-cause dementia was $32 \%$ for low, $25 \%$ for medium, and 5\% for high fitness. Similar results were seen for peak workload/body weight (table 3).

The mean time to dementia onset was 5 years longer for those with high compared to those with medium peak workload. The mean age at dementia onset was 11 years higher among those with high peak workload compared to those with medium peak workload (table 3).

Compared to medium peak workload, the adjusted hazard ratio for all-cause dementia was 0.12 (95\% confidence interval 
Table 2 Dementia incidence stratified by midlife cardiovascular fitness among women followed up for up to 44 years from 1968 to $2012(n=191)$

\begin{tabular}{|c|c|c|c|}
\hline $\begin{array}{l}\text { Crude peak } \\
\text { workload, kilopond } \\
\mathrm{m} / \mathrm{min}(\mathrm{W})^{\mathrm{a}}\end{array}$ & $\begin{array}{l}\text { Participants, } \\
\text { n }\end{array}$ & $\begin{array}{l}\text { All-cause } \\
\text { dementia } \\
\text { incidence, } \\
n(\%)\end{array}$ & $\begin{array}{l}\text { Alzheimer } \\
\text { disease } \\
\text { incidence, } \\
\text { n (\%) }\end{array}$ \\
\hline $\begin{array}{l}\text { Test interrupted } \\
200-400(<48)\end{array}$ & 20 & $9(45)$ & $5(25)$ \\
\hline $450-500(72-80)$ & 39 & $10(26)$ & $4(10)$ \\
\hline $550(88)$ & 9 & $2(22)$ & $2(22)$ \\
\hline $600(96)$ & 36 & $7(19)$ & $6(17)$ \\
\hline 650 (104) & 10 & $4(40)$ & $0(0)$ \\
\hline 700 (112) & 37 & $10(27)$ & $3(8)$ \\
\hline 750 (120) & 11 & $1(9)$ & $0(0)$ \\
\hline 800 (128) & 16 & $1(6)$ & $0(0)$ \\
\hline $850-1,000(\geq 136)$ & 13 & $0(0)$ & $0(0)$ \\
\hline
\end{tabular}

Cardiovascular fitness is assessed by a stepwise-increased ergometer cycling test until exhaustion.

a Peak workload: 1 kilopond $\mathrm{m} / \mathrm{min}=0.16 \mathrm{~W}$.

[CI $0.03-0.54)$ among those with high peak workload and $1.41(0.72-2.79)$ among those with low workload (table 4).

Compared to medium peak workload/body weight, the adjusted hazard ratio for all-cause dementia was 0.35 (95\% CI 0.13-0.97) for those with high fitness and 1.37 (95\% CI $0.62-3.02)$ for those with low fitness.

To minimize the influence of incipient dementia on associations between fitness and dementia, we reanalyzed the data excluding those with dementia onset before 70 years of age and dementia onset before the years 1992 and 2000. This did not change the associations (data not shown).

\section{Discussion}

We found that high cardiovascular fitness in midlife was associated with decreased risk of dementia in a population of women followed up for up to 44 years. High compared to medium fitness decreased the risk of dementia by $88 \%$.

The most pronounced risk reduction was seen among participants with the highest fitness. The 3 previous longitudinal studies on fitness and dementia reported a dose-response relation. The US study, which assessed fitness with a maximal treadmill test, found a decreased dementia risk for every fitness quintile. Similar to our study, the lowest risk was seen among those with highest fitness. ${ }^{8}$ On the other hand, the large register study on Swedish men, which assessed fitness according to a bicycle ergometer test at 18 years of age, found an increased risk of early-onset dementia ( $<60$ years) for those with medium fitness compared to those with high fitness and further increased risk for those with low fitness. ${ }^{9}$ The Finnish study, which used a single question of self-rated fitness, found primarily an increased dementia risk among those with poor fitness. ${ }^{10} \mathrm{~A}$ possible dose-response relation between fitness and dementia risk needs to be further investigated.

We found a very high dementia incidence among those for whom the bicycle test had to be interrupted at submaximal workload. This indicates that adverse cardiovascular processes might be going on in midlife that seem to increase the risk for dementia.

Table 3 Dementia incidence according to midlife cardiovascular fitness among women followed up for up to 44 years from 1968 to $2012(n=191)$

\begin{tabular}{|c|c|c|c|c|}
\hline & $\begin{array}{l}\text { All-cause dementia } \\
\text { incidence, } \mathrm{n}(\%)\end{array}$ & $\begin{array}{l}\text { Alzheimer disease } \\
\text { incidence, } \mathrm{n}(\%)\end{array}$ & $\begin{array}{l}\text { Mean (SD) time to dementia onset } \\
\text { from midlife examination, y }\end{array}$ & $\begin{array}{l}\text { Mean (SD) age at } \\
\text { dementia onset, } y\end{array}$ \\
\hline \multicolumn{5}{|l|}{ Crude peak workload } \\
\hline Low fitness $(n=59)$ & $19(32)$ & $9(15)$ & $26(10)$ & $81(7)$ \\
\hline Medium fitness $(n=92)$ & $23(25)$ & $11(12)$ & $28(10)$ & $79(8)$ \\
\hline High fitness $(n=40)$ & $2(5)^{a}$ & $0(0)^{a}$ & $33(2)^{b}$ & $90(3)$ \\
\hline \multicolumn{5}{|l|}{ Peak workload/body weight } \\
\hline Low fitness $(n=44)$ & $14(33)$ & $9(21)$ & $26(12)$ & $82(8)$ \\
\hline Medium fitness $(n=103)$ & $24(23)$ & $10(10)$ & $29(12)$ & $80(7)$ \\
\hline High fitness $(n=44)$ & $6(14)^{b}$ & $1(2)^{a}$ & $33(11)^{\mathrm{b}}$ & $79(11)$ \\
\hline
\end{tabular}

Fitness assessed by a stepwise-increased ergometer cycling test until exhaustion. Crude peak workload: low fitness = peak work load $\leq 80 \mathrm{~W}$; medium fitness = peak work load 88 to $112 \mathrm{~W}$; and high fitness = peak work load $\geq 120 \mathrm{~W}$. Peak work load/body weight: low fitness = stanine score 1 to $3 ;$ medium fitness = stanine score 4 to 6 ; and high fitness stanine score 7 to 9.

${ }^{a}$ For trend between fitness groups, $p<0.01$ ( $\chi^{2}$ for proportions and analysis of variance for dichotomous).

${ }^{\mathrm{b}}$ For trend between fitness groups, $p<0.05$ ( $\chi^{2}$ for proportions and analysis of variance for dichotomous). 
Table 4 Hazard ratio for association between cardiovascular fitness in midlife and all-cause dementia among women followed up for up to 44 years from 1968 to $2012(n=191)$

\begin{tabular}{lll}
\hline & $\begin{array}{l}\text { Hazard ratio } \\
(95 \% \mathrm{Cl})\end{array}$ & $\begin{array}{l}\text { Adjusted hazard } \\
\text { ratio }^{\mathbf{b}}(\mathbf{9 5 \%} \mathrm{Cl})\end{array}$ \\
\hline Crude peak workload & & \\
\hline Low fitness $(\mathrm{n}=\mathbf{5 9})$ & $1.24(0.67-2.32)$ & $1.41(0.72-2.79)$ \\
\hline Medium fitness $(\mathrm{n}=\mathbf{9 2})$ & 1.0 & 1.0 \\
\hline High fitness $(\mathrm{n}=\mathbf{4 0})$ & $0.12(0.03-0.51)$ & $0.12(0.03-0.54)$ \\
\hline Peak workload/body weight & & \\
\hline Low fitness $(\mathrm{n}=\mathbf{4 4})$ & $1.43(0.74-2.78)$ & $1.37(0.62-3.02)$ \\
\hline Medium fitness $(\mathbf{n}=\mathbf{1 0 3})$ & 1.0 & 1.0 \\
\hline High fitness $(\mathbf{n}=\mathbf{4 4 )}$ & $0.40(0.16-0.99)$ & $0.35(0.13-0.97)$ \\
\hline
\end{tabular}

Abbreviation: $\mathrm{Cl}=$ confidence interval.

Fitness assessed by a stepwise-increased ergometer cycling test until exhaustion. Crude peak workload: low fitness $=$ peak work load $\leq 80 \mathrm{~W}$; medium fitness = peak work load 88 to $112 \mathrm{~W}$; and high fitness = peak work load $\geq 120 \mathrm{~W}$. Peak workload/body weight: low fitness = stanine score 1 to 3; medium fitness = stanine score 4 to 6 ; and high fitness stanine score 7 to 9 . a Cox proportional hazard ratios: adjusted for age and body height.

${ }^{\mathrm{b}}$ Cox proportional hazard ratios: adjusted for age, body height, triglycerides, smoker, hypertension, wine consumption, physical inactivity, and income.

The risk reduction of high fitness on dementia was stronger for the crude peak workload than for peak workload/body weight. This is similar to studies on all-cause mortality in which obese fit individuals have a mortality risk similar to that of normal-weight fit individuals. ${ }^{21}$ This highlights the need for fitness-driven, rather than weight loss-driven, approaches.

Fitness and physical activity are related but not identical. ${ }^{22}$ The hazard ratio in our study was stronger than those reported for physical activity. ${ }^{2,23}$ This is also reported in relation to cardiovascular disease, ${ }^{22}$ indicating that cardiovascular fitness is a more valid measure or that high fitness per se is a stronger protective factor than physical activity. It needs to be emphasized that fitness has a strong genetic component. ${ }^{24}$ Genotype may also modify the association between fitness and dementia. However, evidence is mixed regarding the modifying effect of the $A P O E \& 4$ allele, the main genetic risk factor for dementia. ${ }^{1,10}$ We had data on genes for only a subsample and cannot draw any conclusions about the impact of $A P O E \& 4$ on the relation between fitness and dementia. Certain time periods across the life course might be especially important for the effect of cardiovascular fitness. Factors early in life might increase brain reserve, which moderates the expression of brain damage and age-related changes. ${ }^{25}$ Several dementia-prevention RCTs are on the way, all of which target older persons. One is the multidomain Finnish Geriatric Intervention Study to Prevent Cognitive Impairment and Disability (FINGER) study, which targets older persons with cardiovascular risk factors. ${ }^{26}$ This study reported promising results on cognition after 2 years. Another study targeted sedentary older persons and included moderate-intensity aerobic (walking) and strength training, ${ }^{27}$ but it found no effect on cognition after 2 years. Recently, a 6-year multidomain intervention reported no effects on dementia incidence. ${ }^{28}$ Future intervention studies are needed that target whether the actual improvement in cardiovascular fitness (and muscle strength) is the pathway between physical activity and cognitive functioning. In practice, it will take a very long time to have RCTs that examine the effect of improved midlife (or childhood) fitness on dementia. Meanwhile, longitudinal observational studies such as ours can provide information.

Several mechanisms might be involved in how fitness reduces dementia risk. These include both indirect effects such as influence on hypertension, hypercholesterolemia, obesity, and diabetes mellitus and directs effects on the brain, with, for example, enhancement of neuronal structures, neurotransmitter synthesis, and growth factors. ${ }^{1,29}$ Our study and the 3 other longitudinal studies on fitness and dementia ${ }^{8-10}$ show similar results in unadjusted analyses and analyses adjusted for indirect effects. This indicates that direct effects on the brain need to be further investigated. In line with this, a recent study found that lower cardiovascular fitness was associated with smaller brain volume 2 decades later. ${ }^{30}$ The brain regions that seem most influenced by physical activity are those that are also vulnerable to age-related changes and early pathologic changes in Alzheimer disease such as the hippocampus. ${ }^{31}$ Further research on long-term direct effects of fitness on brain structure is needed to improve strategies for dementia prevention.

Major strengths of our study are the objective assessment of fitness, the fact that baseline examinations were carried out in midlife, the 44 years of follow-up, that the dementia diagnosis was made by neuropsychiatrist according to extensive examinations, the population-based sample, and the extensive collection of potential confounders. However, there are several limitations. First, this study had an observational design; therefore, we cannot draw conclusions on cause and effect. Second, the sample was relatively small, leading to a lack of statistical power and limiting the possibility for subanalyses. Third, the study includes a relatively homogeneous sample of Swedish women. We thus cannot generalize to other populations. In addition, women in the study probably received more medical care than other women because persons in whom we identified pathologic conditions (e.g., hypertension) were referred for medical treatment. Fourth, cumulative dropout is a problem in long-term follow-up studies. While this problem was, to some extent, alleviated by the use of hospital registry data for those lost to follow-up, this probably results in an underestimation of the number of dementia cases. It should be noted that almost all people in Sweden receive hospital treatment within the public health system, and the Swedish Hospital Discharge Register covers the entire country. Fifth, the exercise test in 1968 measured work capacity, not maximal oxygen consumption with expired gas 
analysis, the gold standard for cardiorespiratory fitness. Sixth, the maximal workload for the women in our study is lower compared to previously reported reference values. ${ }^{32}$ This might be due to different procedures for the exercise test. Seventh, we did not have data on changes in fitness across the life course. Eighth, competing risk may influence the results of a study with long-follow-up because both dementia and low fitness may increase the risk for death. This might result in an underestimation of the association between these conditions. The use of risk-years in the Cox regression analyses partly takes care of competing risk because persons who die earlier will contribute fewer years.

Our findings indicate that high cardiovascular fitness in midlife is associated with decreased risk of dementia. Improved cardiovascular fitness in midlife might be a modifiable factor to delay or prevent dementia. Findings are not causal, and future research needs to focus on whether improved fitness could have positive effects on dementia risk and when during the life course a high cardiovascular fitness is most important.

\section{Authors contributions}

H.H. did the literature search, data analyses, data interpretation, created the figures and drafted the manuscript. L. J., X.G., G.G., S.K., S.Ö., and I.S. did data interpretation, reviewed, modified, and approved the manuscript.

\section{Acknowledgment}

The authors are deeply grateful to Calle Bengtsson (in memoriam), the initiator of the PWWS study, and Gunnar Grimby, who in cooperation with Calle Bengtsson examined all the women in 1968. They also thank all the women who participated in the study.

\section{Study funding}

This work was supported by the Forte-Centre Aging and Health: Centre for Capability in Ageing (AGECAP). It was also supported by grants from the Swedish Research Council for Health, Working Life and Welfare (2004-0145, 20060596, 2008-1111, 2010-0870, Epilife 2006-1506, AGECAP 2013-2300, 2013-2496), the Alzheimer's Association Stephanie B. Overstreet Scholars (IIRG-00-2159, 20081229), the Alzheimer's Association Zenith Award (ZEN-013151), the Swedish Research Council (Nos. 11267, 2005-8460, 825-2007-7462, 825-2012-5041, 2013-8717, 2015-02830), Sahlgrenska University Hospital (ALF), the Bank of Sweden Tercentary Foundation, Swedish Brain Power, Hjärnfonden, Alzheimerfonden, Konung Gustaf V: soch Drottning Victorias frimurarestiftelse, Stiftelsen Gamla Tjänarinnor, Hjalmar Svenssons Foundation, Systrarna Greta Johansson and Brita Anderssons minnesfond, Axel Linders stiftelse, Stiftelsen Ragnhild o Einar Lundström, Stohnes stiftelse, Lundgrenska stiftelserna, and Svensk-Franska stiftelsen. The funding sources have no involvement in data collection, analysis, or interpretation; design; recruitment; or any aspect pertinent to the study.

\section{Disclosure}

The authors report no disclosures relevant to the manuscript. Go to Neurology.org/ $\mathrm{N}$ for full disclosures.

Received July 6, 2017. Accepted in final form January 4, 2018.

\section{References}

1. Rolland Y, Abellan van Kan G, Vellas B. Physical activity and Alzheimer's disease: from prevention to therapeutic perspectives. J Am Med Dir Assoc 2008;9: 390-405.

2. Hamer M, Chida Y. Physical activity and risk of neurodegenerative disease: a systematic review of prospective evidence. Psychol Med 2009;39:3-11.

3. Blondell SJ, Hammersley-Mather R, Veerman JL. Does physical activity prevent cognitive decline and dementia? A systematic review and meta-analysis of longitudinal studies. BMC Public Health 2014;14:510.

4. Miller DI, Taler V, Davidson PS, Messier C. Measuring the impact of exercise on cognitive aging: methodological issues. Neurobiol Aging 2012;33:622. e29-622.e43.

5. Angevaren M, Aufdemkampe G, Verhaar HJ, Aleman A, Vanhees L. Physical activity and enhanced fitness to improve cognitive function in older people without known cognitive impairment. Cochrane Database Syst Rev 2008;2: CD005381

6. Smith PJ, Blumenthal JA, Hoffman BM, et al. Aerobic exercise and neurocognitive performance: a meta-analytic review of randomized controlled trials. Psychosom Med 2010;72:239-252.

7. Young J, Angevaren M, Rusted J, Tabet N. Aerobic exercise to improve cognitive function in older people without known cognitive impairment. Cochrane Database Syst Rev 2015;4:Cd005381

8. Defina LF, Willis BL, Radford NB, et al. The association between midlife cardiorespiratory fitness levels and later-life dementia: a cohort study. Ann Intern Med 2013; 158:162-168.

9. Nyberg J, Aberg MA, Schioler L, et al. Cardiovascular and cognitive fitness at age 18 and risk of early-onset dementia. Brain 2014;137:1514-1523.

10. Kulmala J, Solomon A, Kareholt I, et al. Association between mid- to late life physical fitness and dementia: evidence from the CAIDE study. J Intern Med 2014;276: 296-307.

11. Barnes DE, Yaffe K. The projected effect of risk factor reduction on Alzheimer's disease prevalence. Lancet Neurol 2011;10:819-828.

12. Norton S, Matthews FE, Barnes DE, Yaffe K, Brayne C. Potential for primary prevention of Alzheimer's disease: analysis of population based data. Lancet Neurol 2014; 13:788-794.

13. Bengtsson C, Blohme G, Hallberg L, et al. The study of women in Gothenburg 1968-1969: a population study: general design, purpose and sampling results. Acta Med Scand 1973;193:311-318.

14. Bengtsson C, Vedin JA, Grimby G, et al. Maximal work performance test in middleaged women: results from a population study. Scand J Clin Lab Invest 1978;38: 181-188.

15. Borg G. Borg's Perceived Exertion and Pain Scales. Champaign: Human Kinetics; 1998.

16. Johansson L, Guo X, Waern M, et al. Midlife psychological stress and risk of dementia: a 35-year longitudinal population study. Brain 2010;133:2217-2224.

17. Ludvigsson JF, Andersson E, Ekbom A, et al. External review and validation of the Swedish National Inpatient Register. BMC Public Health 2011;11:450.

18. Guo X, Waern M, Sjogren K, et al. Midlife respiratory function and incidence of Alzheimer's disease: a 29-year longitudinal study in women. Neurobiol Aging 2007; 28:343-350.

19. Saltin B, Grimby G. Physiological analysis of middle-aged and old former athletes: comparison with still active athletes of the same ages. Circulation 1968;38: 1104-1115.

20. Grimby G, Borjesson M, Jonsdottir IH, Schnohr P, Thelle DS, Saltin B. The "SaltinGrimby Physical Activity Level Scale” and its application to health research. Scand J Med Sci Sports 2015;25(suppl 4):119-125.

21. Barry VW, Baruth M, Beets MW, Durstine JL, Liu J, Blair SN. Fitness vs. fatness on allcause mortality: a meta-analysis. Prog Cardiovasc Dis 2014;56:382-390.

22. DeFina LF, Haskell WL, Willis BL, et al. Physical activity versus cardiorespiratory fitness: two (partly) distinct components of cardiovascular health? Prog Cardiovasc Dis 2015;57:324-329.

23. Sofi F, Valecchi D, Bacci D, et al. Physical activity and risk of cognitive decline: a metaanalysis of prospective studies. J Intern Med 2011;269:107-117.

24. Bouchard C, Dionne FT, Simoneau JA, Boulay MR. Genetics of aerobic and anaerobic performances. Exerc Sport Sci Rev 1992;20:27-58.

25. Nithianantharajah J, Hannan AJ. The neurobiology of brain and cognitive reserve: mental and physical activity as modulators of brain disorders. Prog Neurobiol 2009; 89:369-382.

26. Ngandu T, Lehtisalo J, Solomon A, et al. A 2 year multidomain intervention of diet, exercise, cognitive training, and vascular risk monitoring versus control to prevent cognitive decline in at-risk elderly people (FINGER): a randomised controlled trial. Lancet 2015;385:2255-2263.

27. Sink KM, Espeland MA, Castro CM, et al. Effect of a 24-month physical activity intervention vs health education on cognitive outcomes in sedentary older adults: the LIFE randomized trial. JAMA 2015;314:781-790. 
van Charante EP, Richard E, Eurelings LS, et al. Effectiveness of a 6-year multidomain vascular care intervention to prevent dementia (preDIVA): a cluster-randomised controlled trial. Lancet 2016;388:797-805.

29. Brown BM, Peiffer JJ, Martins RN. Multiple effects of physical activity on molecular and cognitive signs of brain aging: can exercise slow neurodegeneration and delay Alzheimer's disease? Mol Psychiatry 2013;18: $864-874$.
30. Spartano NL, Himali JJ, Beiser AS, et al. Midlife exercise blood pressure, heart rate, and fitness relate to brain volume 2 decades later. Neurology 2016;86: 1313-1319.

31. Thomas AG, Dennis A, Bandettini PA, Johansen-Berg H. The effects of aerobic activity on brain structure. Front Psychol 2012;3:86.

32. Loe H, Rognmo O, Saltin B, Wisloff U. Aerobic capacity reference data in 3816 healthy men and women 20-90 years. PLoS One 2013;8:e64319. 


\title{
Midlife cardiovascular fitness and dementia
}

\author{
A 44-year longitudinal population study in women
}

Helena Hörder, PhD, Lena Johansson, PhD, XinXin Guo, MD, PhD, Gunnar Grimby, MD, Silke Kern, MD, PhD, Svante Östling, MD, and Ingmar Skoog, MD

Cite as: Neurology ${ }^{\circledR}$ 2018;90:e1298-e1305. doi:10.1212/WNL.0000000000005290
Correspondence

Dr. Hörder

Helena.Horder@neuro.gu.

se

\section{Study question}

Does increased cardiovascular fitness during midlife reduce the risk of dementia in adult women, and how far into the lifespan does this protection extend?

\section{Summary answer}

Among Swedish women aged 38-60 years, high cardiovascular fitness levels reduced dementia risks-incidence, age at onset, and time to onset-over a 44-year period.

\section{What is known and what this paper adds}

Previous analyses of self-reported data show a strong link between physical activity and decreased risk for dementia within 20 years of testing. This longitudinal study objectively measured cardiovascular fitness and the risk of dementia in women during their midlife stage.

\section{Participants and setting}

The study comprised 191 participants from the Swedish Population Register based on birth dates who underwent exercise testing.

\section{Design, size, and duration}

Participants were assigned to low-, medium-, or high-baseline cardiovascular fitness levels, as determined by peak workload results in ergometer cycling tests to exhaustion. Peak workload was defined as work capacity, measured using physiologic markers and perceived exertion. Dementia assessments were performed periodically during $1968-2012$ (mean $=29$ years). Dementia was diagnosed using neuropsychiatric examinations, close informant interviews, and evaluations of medical records, and from the Swedish Hospital Discharge Register.

\section{Main results and the role of chance}

High cardiovascular fitness levels during midlife decreased the risk of dementia. Compared to the medium fitness group, the high fitness group showed an $88 \%$ decrease in dementia incidence, 5 years longer to onset, and 11 years higher mean age at onset. The highest fitness levels presented with the lowest dementia risk, suggesting a dose-response association. Hazard ratios for fitness are higher than those reported for physical

\begin{tabular}{lll}
\hline & $\begin{array}{l}\text { Hazard ratio } \\
(\mathbf{9 5 \%} \mathrm{Cl})\end{array}$ & $\begin{array}{l}\text { Adjusted hazard } \\
\text { ratio }(95 \% \mathrm{Cl})\end{array}$ \\
\hline Crude peak workload & & \\
\hline Low fitness $(\mathbf{n}=\mathbf{5 9})$ & $1.24(0.67-2.32)$ & $1.41(0.72-2.79)$ \\
\hline Medium fitness $(\mathbf{n}=\mathbf{9 2})$ & 1.0 & 1.0 \\
\hline High fitness $(\mathbf{n}=\mathbf{4 0})$ & $0.12(0.03-0.51)$ & $0.12(0.03-0.54)$ \\
\hline Peak workload/body weight & & \\
\hline Low fitness $(\mathbf{n}=\mathbf{4 4 )}$ & $1.43(0.74-2.78)$ & $1.37(0.62-3.02)$ \\
\hline Medium fitness $(\mathbf{n}=\mathbf{1 0 3})$ & 1.0 & 1.0 \\
\hline High fitness $(\mathbf{n}=\mathbf{4 4 )}$ & $0.40(0.16-0.99)$ & $0.35(0.13-0.97)$ \\
\hline
\end{tabular}

activity, indicating fitness is a more valid measure and provides greater protection.

\section{Bias, confounding, and other reasons for caution}

An observational study cannot identify cause-and-effect relationships. The relatively small sample size restricted statistical power and sub-analyses. Participants received more medical monitoring and care than the general population. Long-term data collection may result in underestimated findings due to cumulative drop-outs and competing mortality risks. Fitness levels are strongly influenced by genetic factors. Work capacity is a less accurate measure of fitness than $\mathrm{O}_{2}$ consumption. There is also a need to confirm that fitness is the mechanism connecting physical activity and cognitive function. Potential confounders include education, smoking, leisure/work activity, wine consumption, hypertension, body height/weight, BMI, serum cholesterol/triglycerides, diabetes mellitus, myocardial infarction/angina pectoris, stroke.

\section{Generalizability to other populations}

The study used a relatively homogenous group of Swedish women, which limits generalization to other populations.

\section{Study funding/potential competing interests}

The study was funded by a group of university, government and foundation grants. Go to Neurology.org/ $\mathrm{N}$ for full disclosures. 


\section{Neurology}

\section{Midlife cardiovascular fitness and dementia: A 44-year longitudinal population study in women}

Helena Hörder, Lena Johansson, XinXin Guo, et al. Neurology 2018;90;e1298-e1305 Published Online before print March 14, 2018

DOI 10.1212/WNL.0000000000005290

\section{This information is current as of March 14, 2018}

\section{Updated Information \&} Services

References

Citations

Subspecialty Collections

Permissions \& Licensing

Reprints including high resolution figures, can be found at: http://n.neurology.org/content/90/15/e1298.full

This article cites 31 articles, 3 of which you can access for free at: http://n.neurology.org/content/90/15/e1298.full\#ref-list-1

This article has been cited by 6 HighWire-hosted articles: http://n.neurology.org/content/90/15/e1298.full\#\#otherarticles

This article, along with others on similar topics, appears in the following collection(s):

All Cognitive Disorders/Dementia

http://n.neurology.org/cgi/collection/all_cognitive_disorders_dementia Alzheimer's disease

http://n.neurology.org/cgi/collection/alzheimers_disease

Screening in epidemiology

http://n.neurology.org/cgi/collection/screening_in_epidemiology

Information about reproducing this article in parts (figures,tables) or in its entirety can be found online at:

http://www.neurology.org/about/about_the_journal\#permissions

Information about ordering reprints can be found online:

http://n.neurology.org/subscribers/advertise

Neurology $\mathbb{B}$ is the official journal of the American Academy of Neurology. Published continuously since 1951 , it is now a weekly with 48 issues per year. Copyright Copyright (C) 2018 The Author(s). Published by Wolters Kluwer Health, Inc. on behalf of the American Academy of Neurology.. All rights reserved. Print ISSN: 0028-3878. Online ISSN: 1526-632X.

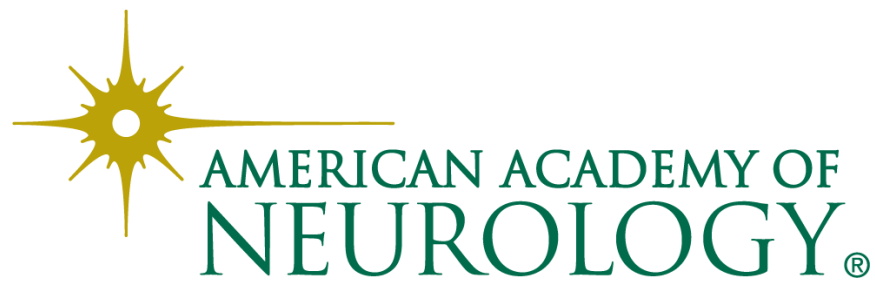

